Journal of the Scholarship of Teaching and Learning, Vol. 21, No. 1, April 2021, pp.21-24.

doi: 10.14434/josotl.v21i1.30549

\title{
The Impact of Service-Oriented Undergraduate Research on an Ongoing Participatory Community Action Research Project at Homeless Shelters
}

\author{
Jennifer L. Zicka \\ University of Dayton \\ Roger N. Reeb \\ University of Dayton \\ rreeb1@udayton.edu
}

\section{Introduction}

This article is a genuine contribution between an undergraduate student (Jennifer Zicka) and her mentor (Dr. Roger Reeb). Jennifer made unique contributions to an ongoing project that empowers and supports guests at homeless shelters as they strive to overcome personal challenges and obstacles related to homelessness. After a brief description of the Project, we celebrate Jennifer's unique contributions, which sets the stage for the centerpiece of the article - Jennifer's heartfelt reflection on how this experiential learning contributed to her civic-related development, personal growth, and the pursuit of her dream career.

\section{Background}

The Participatory Community Action Research Project at Homeless Shelters represents a decade-old collaboration between Dr. Reeb (Professor of Psychology) at the University of Dayton (UD) and St. Vincent de Paul (Dayton, OH). The Project implements behavioral activation for shelter residents by providing them opportunities to engage in productive activities that lead to response-contingent reinforcement (a rewarding experience following an accomplishment). The response-contingent reinforcement increases productive behavior and improvements in general empowerment (sense of mastery), quality of life, mood, and reasoning skills (Kanter et al., 2010). To our knowledge, there is no prior documentation of using behavioral activation in homeless shelters. At UD, the Project is affiliated with the Human Rights Center, the Hanley Sustainability Institute, and the Fitz Center for Leadership in Community. Examples of community partners in Montgomery County (Ohio) include: the Office of Re-Entry; the National Alliance on Mental Illness; Narcotics Anonymous; Alcoholics Anonymous; Hospice of Dayton; and the Ohio State University Agricultural Extension.

Following an orientation, service-learning students work alongside graduate students, faculty, and community partners to provide three interrelated categories of behavioral activation sessions. One category of sessions enhances self-sufficiency/empowerment, such as computer training, job preparation, and improving access to community resources. A second category of sessions improve social support and coping of guests, including stress management training, support groups, and prevention programs. Finally, the third category of sessions improve the shelter's social climate through events such as cookouts and art and music activities, which enhance the establishment of rapport among shelter guests and students, making the other two categories of sessions possible. The Project also hosts community partners to provide sessions to guests.

Over 1,500 shelter guests have participated in the Project, and quantitative and qualitative research documents the Project's benefit for their psychological development (Reeb, Elvers, et al., 
2017; Reeb et al., 2021). Well over 300 service-learning students have assisted with this Project, many across multiple semesters. The Project is associated with Dr. Reeb's course, Engaged Scholarship for Homelessness: A Service-Learning Course, though students can assist by enrolling in other credit-bearing service-learning courses. Throughout the semester, students reflect on social justice and human rights issues that are pertinent to their service activities. Quantitative and qualitative research documents civic-related development in these students, such as decreases in stigmatizing attitudes, increases in self-efficacy (confidence) for community service, and improvements in awareness of privilege and oppression (Reeb, Hunt, et al., 2017; Reeb et al., 2021). With our research infrastructure, students assist in sustaining the Project, and some students, such as Jennifer, even develop and conduct individualized studies that reflect their interests and career aspirations.

\section{Undergraduate Contributes to Research Project and Pursues Career Aspirations}

Jennifer graduated from UD with a Bachelor of Science in psychology and a minor in biology, while also obtaining a Certificate in Deaf Studies from the University of Cincinnati. As an undergraduate, she assisted with various components of the Project over four semesters, including a summer semester supported by the Dean's Summer Fellowship Program, which is administered through the College of Arts and Sciences. Further, Jennifer completed an independent research capstone by conducting a unique and innovative study that coincided with her career goal of becoming an Audiologist who works with disadvantaged individuals. Her research examined the feasibility of teaching American Sign Language (ASL) in homeless shelters, which is important because individuals in poverty are more likely to suffer hearing impairments related to prematurity and low birthrate. In turn, individuals with hearing impairment face significant educational and occupational disadvantages (Kubba, et al., 2004; World Health Organization, 2016), which are exacerbated by homelessness (Weinreb et al., 2007), as documented in the authors' own community (Target Dayton News, 2015). An article in New York Daily News (2005) illustrates the demand for ASL resources in shelters: "The city's Department of Homeless Services agreed...to provide sign language interpreters to deaf people living in homeless shelters [and thereby] ending... lawsuits charging that the city was discriminating against the hearing-impaired." In fact, lack of such resources for deaf individuals in poverty is an international human rights issue (World Federation of the Deaf, 2016). The World Health Organization (2016) stated:

In developing countries, children with hearing loss and deafness rarely receive any schooling. Adults with hearing loss also have a much higher unemployment rate. Among those who are employed, a higher percentage of people with hearing loss are in the lower grades of employment compared with the general workforce.

Programs such as Discovering Deaf Worlds have shown the benefit of providing sign language resources to those in poverty, including those in developing countries (Borgen Project, 2018).

The first author conducted a pilot study to determine the feasibility of providing ASL training in a chaotic homeless shelter and to ascertain if doing so would be beneficial. This pilot study included 24 shelter guests who volunteered to participate in ASL sessions and completed a brief validated measure of perceived benefits. As hypothesized, shelter guests perceived the ASL sessions as beneficial, meaningful, important, worthy of repeating, and enjoyable.

In the follow-up study, 34 shelter residents in ASL sessions completed pre- and post-session measures of both receptive and expressive language (adapted from the Central Institute for the Deaf). As hypothesized, shelter guests showed significant pre- to post-session improvements in both Receptive ASL and Expressive ASL. Quantitative findings were supported and illustrated in qualitive data (written comments by residents).

Journal of the Scholarship of Teaching and Learning, Vol. 21, No. 1, April 2021. josotl.indiana.edu 
Jennifer's research was presented at the Stander Symposium at UD (Zicka, 2019) and the Midwestern Psychological Association (Zicka et al., 2019). Alongside her experience in research and presentation, Jennifer recognizes the impact of the experiential learning on her civic-related development and professional growth, as illustrated in her reflection below:

Although I completed coursework on deaf-related stigma, I was unaware of the double stigma experienced by deaf individuals who are experiencing homelessness. One deaf resident told me that people stay away from him and think he "talks funny." Some deaf residents felt uncomfortable and unable to participate in our behavioral activation sessions, but with my support, these individuals participated. Introducing ASL to the shelters reduced some of the stigma surrounding deafness, and this is consistent with research showing that reducing stigma involves both education and contact with the stigmatized population.

My work on this Project, supported by my new knowledge of the relationship between poverty and deafness and the need for ASL support in homeless shelters, increased my awareness of privilege and oppression. Since I was lucky enough to be born into an economically comfortable family, I never needed something without being able to get it. Things such as going to a doctor's appointment, having access to a phone, obtaining employment, and finding transportation are major struggles for homeless individuals, and such struggles are exacerbated by disabilities and health problems.

My experiences on this Project over four semesters, accompanied by my Independent Research Capstone and my individualized work with deaf residents, greatly contributed to my professional development; that is, it enhanced my sense of community service self-efficacy, which is a person's confidence in making contributions to the community. In addition, I learned a great deal about agencies that provide resources for deaf individuals (e.g., DeafLEAD; Dayton Deaf Community Resource Center), and I provided the shelters with contact information for these resources. Due to my work on this ongoing Project, as well as my other academic accomplishments, I was awarded the Dean Leonard A. Mann, S.M. Award of Excellence at UD, which recognizes the outstanding senior in the College whose academic record and record of service embody the three characteristics of Learn, Lead, and Serve. Furthermore, after graduating from UD, I began taking pre-requisite classes to pursue my dream of becoming an Audiologist. While taking classes, I continued community service related to homelessness and also engaged in career-related research at a nearby university. Despite complications revolving around COVID-19, I applied to graduate schools, and I was accepted to Utah State University's Doctorate of Audiology Program. My immersion in research projects, such as the homeless shelter project described here, prepared me for graduate study in Audiology by belping me to understand how best to work with diverse (and disadvantaged) populations. With this experience and knowledge, I will see through stigma surrounding disability (and disadvantage) and provide person-centered clinical care.

\section{Future of the Project: An Undergraduate Student's Legacy}

Due in part to the dedication of students such as Jennifer, we have sustained the Project's work and funding in the face of COVID-19, though much of our recent work has been remote. Despite COVID-19 restrictions, we even sustained the Shelter Farm, which was established as part of the Project in 2017 and in collaboration with The Ohio State University. The Shelter Farm, which exists on the grounds of the shelter in a food desert, has yielded about 5,000 pounds of produce for shelter guests. The Shelter Farm is pertinent to this article, because Jennifer was one student who contributed to it as she worked on the Project, as UD President Eric Spina noted on his blog ("A Sign of Hope"; https://udayton.edu/blogs/president/2018/10/a sign of hope.php.) wherein he comments on Jennifer's presentation to UD's Board of Trustees regarding her overall work on this Project.

Journal of the Scholarship of Teaching and Learning, Vol. 21, No. 1, April 2021. josotl.indiana.edu 


\section{References}

Borgen Project (2018). Sign language education in developing countries. Retrieved from: https://borgenproject.org/sign-language-developing-countries/

Central Institute for the Deaf. (n.d.). CID early childhood vocabulary rating forms. Retrieved from: https://professionals.cid.edu/product/cid-early-childhood-vocabulary-rating-forms/

Deaf Community Resource Center. (n.d.). Retrieved from: https://www.dcrcohio.org/

DeafLEAD. (n.d.). Retrieved from: https://www.deafinc.org/deaflead/services.html

Discovering Deaf Worlds. (n.d.). Retrieved from: https://www.deafworlds.org

Kubba, H., MacAndie, C., Ritchie, \& MacFarlane, M. (2004). Is deafness a disease of poverty? Association between socioeconomic deprivation and congenital hearing impairment. International Journal of Audiology, 43(3), 123-1125. https://doi.org/10.1080/14992020400050017

Los Angeles Times (1990). Deaf struggle for help from homeless agencies. Retrieved from: http://articles.latimes.com/1990-03-07/news/ga-1855 1 union-station

New York Daily News (2015). Deaf people in NYC homeless shelters will gain access to sign language interpreters. Retrieved from: https://www.nydailynews.com/new-york/nyc-deafhomeless-people-gain-interpreters-shelters-article-1.2404490

Reeb, R.N., Elvers, G., et al. (2017, September). Participatory community action research in homeless shelters: Outcomes for homeless shelter residents [Paper presentation]. International Association for Research on Service-Learning and Community Engagement, Galway, Ireland.

Reeb, R.N., Elvers, G., Hunt, C.A., et al. (2020). Participatory community action research in homeless shelters: Outcomes for shelter residents and service-learning research assistants. [Manuscript in revise and resubmit for publication]. Department of Psychology, University of Dayton.

Reeb, R.N., Hunt, C., Elvers, G., Holcomb, J., Katsuyama, R., Fadoir, N., Wetter, S., O’Koon, Longstreth, M., Nelson, M., \& Hartman, C. (2017, September). Outcomes for service-learning students implementing participatory community action research in homeless shelters [Paper presentation]. International Association for Research on Service-Learning and Community Engagement, Galway, Ireland.

Target Dayton News (2015). Deaf and homeless. Retrieved from: http://www.targetdayton.com/hp wordpress/wp-content/uploads/2015/09/SeptNewsletter-2015.pdf

United Nations General Assembly. (1948). Universal declaration of human rights. Retrieved from: https://www.ohchr.org/EN/UDHR/Documents/UDHR Translations/eng.pdf

Weinreb, L., Gelberg, L., Arangua, L \& Sullivan, M. (2007). Homelessness and health problems. In D. Levinson, \& M. Ross (Eds), Homelessness handbook (pp. 188-198).

World Federation of the Deaf (2016). Advancing human rights and sign language worldwide. Retrieved from: http://wfdeaf.org/our-work/human-rights-of-the-deaf/

World Health Organization (2018). Deafness and hearing loss. Retrieved from: https://www.who.int/en/news-room/fact-sheets/detail/deafness-and-hearing-loss

Zicka, J. (2019, April). Behavioral activation research project in homeless shelters. Presented at the Stander Symposium at the University of Dayton, Dayton, $\mathrm{OH}$.

Zicka, J., Reeb, R.N., \& Gibbins, K. (2019, April). Efficacy of teaching American Sign Language in homeless shelters. Poster presented at the Midwestern Psychological Association, Chicago, IL. 